\title{
The Sliding Isolation Pendulum for the seismic protection of buildings
}

\author{
P. Huber ${ }^{1} \&$ R. Medeot ${ }^{2}$ \\ ${ }^{1}$ MAURER SÖHNE GmbH \& Co. KG, Germany \\ ${ }^{2}$ Consultant, Italy
}

\begin{abstract}
The Sliding Isolation Pendulum (SIP) is a new seismic isolator that can be ideally derived from a conventional PTFE spherical sliding bearing in which the flat surface that accommodates translation movements has been substituted by a concave sliding surface. This important, albeit simple modification, transforms a structural bearing into a perfect seismic isolator providing all necessary functions of a seismic isolation system for a building. Besides the adoption of the curved sliding surface, the Sliding Isolation Pendulum differs from a conventional PTFE spherical sliding bearing in its use of a new elasto-plastic sliding material and certain design details that translate into an enhanced level of performance. This paper illustrates the innovative aspects that distinguish the Sliding Isolation Pendulum from other existing similar devices, the substantial advantages it can accrue vis-à-vis previously used technologies, as well as the practical applications.
\end{abstract}

Keywords: seismic isolator, seismic hardware, sliding pendulum, Friction Pendulum, seismic protection.

\section{Introduction}

In 1970 the Company Kreutz/Germany invented and patented the spherical bearing (Fig. 1, left) to accommodate relative rotations and displacements effectively with the sliding couple PTFE (Teflon) against stainless steel.

Based on the principles of the spherical bearing, in 1988 the Friction Pendulum bearing was invented by Victor Zayas [1]. Ideally, the Friction Pendulum can be derived from a spherical bearing in which the flat surface that accommodates translation movements has been substituted by a curved surface (Fig. 1, right). 

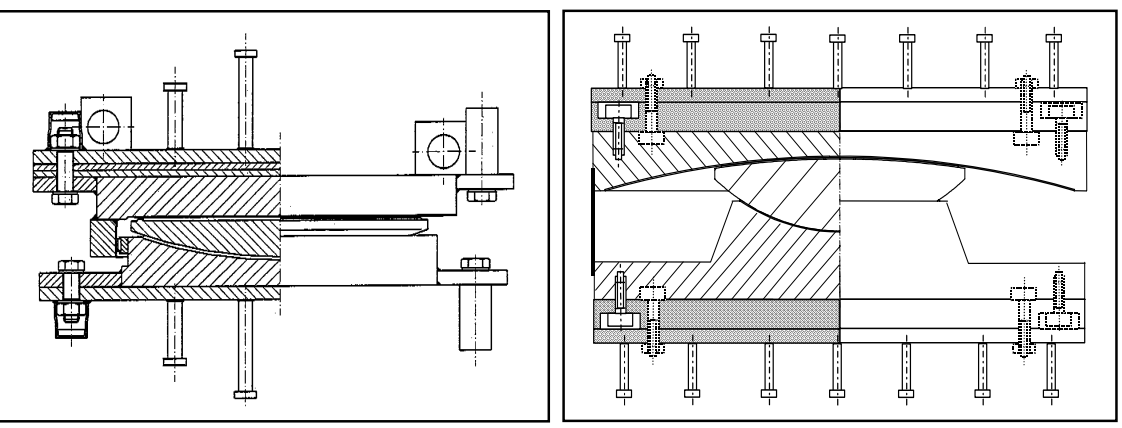

Figure 1: Spherical Bearing by KREUTZ (left) and Pendulum Isolator Friction Pendulum by Zayas (right).

This important and simple modification transforms a structural bearing into a perfect seismic isolator. As a matter of fact, the four fundamental functions of a seismic isolation system are the following (Braun [2]):

- Transmission of Vertical loads.

- Lateral Flexibility on the horizontal plane.

- Energy Dissipation.

- Self-centering capability.

Transmission of Vertical loads as well as accommodation of relative rotations can be implemented through the use of curved bearing liners. Lateral Flexibility on the horizontal plane is achieved through the main sliding surface. Energy Dissipation is produced by the dynamic friction force of the main sliding surface. And last, but not least, Self-centering capability can be provided by the restoring force given by the combination of gravity and the geometry of the main sliding surface (Medeot [3]).

From the above, we can conclude that the Friction Pendulum is a seismic isolator that provides the aforesaid four functions through an appropriate arrangement of curved sliding surfaces, exploiting the characteristics of a pendulum to control the natural period of the isolated structure.

Undoubtedly, the introduction of the Friction Pendulum significantly contributed to the diffusion of seismic isolation as a modern design approach to protect the most diverse types of structures (buildings, bridges, industrial plants, NLG tanks, etc.) from the direst effects of an earthquake attack. In many cases, it represents the only viable solution. For example, when there is a requirement for long natural periods to which relevant displacements are associated.

Considering the above requirements, the principle design of the spherical bearing and the Friction Pendulum, a new device called Sliding Isolation Pendulum (SIP) was developed resisting seismic design impacts without any sort of wear and without changing its function characteristics even after several earthquakes. 


\section{Technical characteristics of sliding isolation pendulum (SIP)}

The main issues about the SIP devices are the conformity with existing standards, the applied sliding couples, the wear resistance, the design and the resulting reliable long term performance.

\subsection{Conformity with existing norms}

The seismic isolators are designed to satisfy two load cases simultaneously, which has been often forgotten. Many designers see only the seismic load case and do not consider service ability after an earthquake or any effects of the earthquake onto the device. The goal is that the isolator is operating under service load and seismic condition according to existing European Norms like EN1998-1.

The SIP is in addition according to the prEN15129 "Anti seismic devices" (Medeot [4]), which specifies the tolerances, behaviour, sliding couple requirements, wear, quality management, testing and general function of curved sliding isolators like the SIP device for service and for the seismic load case.

For spherical bearings and the sliding couple for the SIP consisting of a special polyethylene liner material against stainless steel respectively a European Technical Approval (ETA) (Maurer Söhne [5]) exists. This ETA provides design details, material details, quality requirements and general rules for the devices, that designers can check the isolator accordingly.

\subsection{Sliding couple}

The SIP is a sliding isolator, i.e. the device is horizontally moving during an earthquake.

The lateral displacements occur within the primary sliding surface (Figs. $2 \& 3$ ).

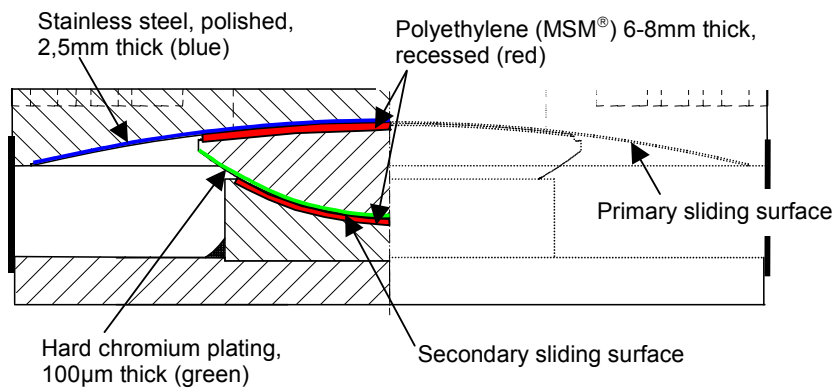

Figure 2: $\quad$ Sliding Isolation Pendulum (SIP).

While displacing laterally the spherical part is moving along the concave surface and high edge stresses are created in the sliding liner material at the front edge in displacement direction. Due to the defined elasto-plastic deformation 
behaviour of the applied polyethylene material these stress concentrations are well distributed within the polyethylene and do not result in any wear or damages of the polyethylene or in scratches on the stainless steel sliding sheet.

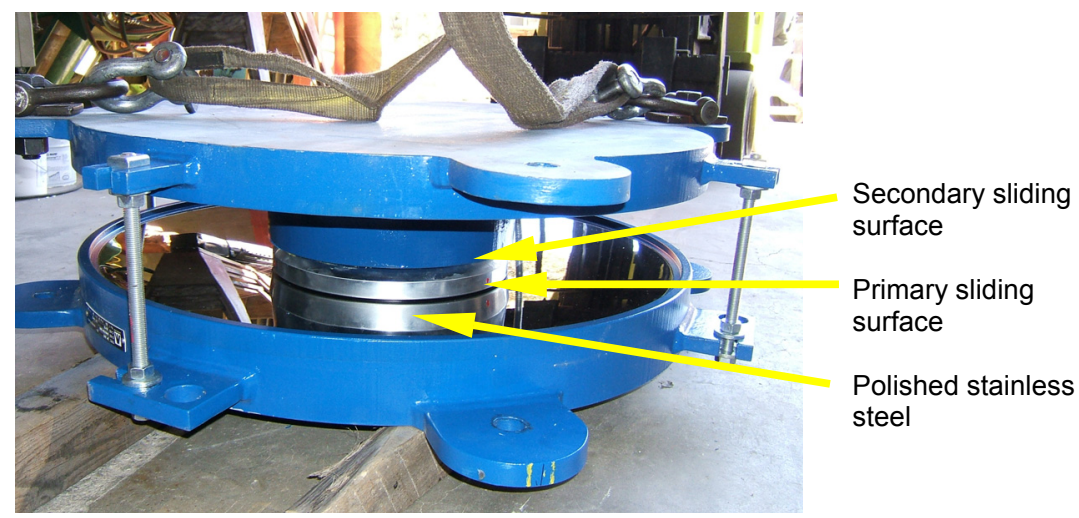

Figure 3: $\quad$ SIP device placed with the sliding surface at the bottom.

The elasto-plastic deformation behaviour grants for full surface contact of the polyethylene and the stainless steel, while the maximum characteristic compressive strength capacity of the applied special polyethylene $\mathrm{MSM}^{\circledR}$ is 180 MPa (Braun [6]).

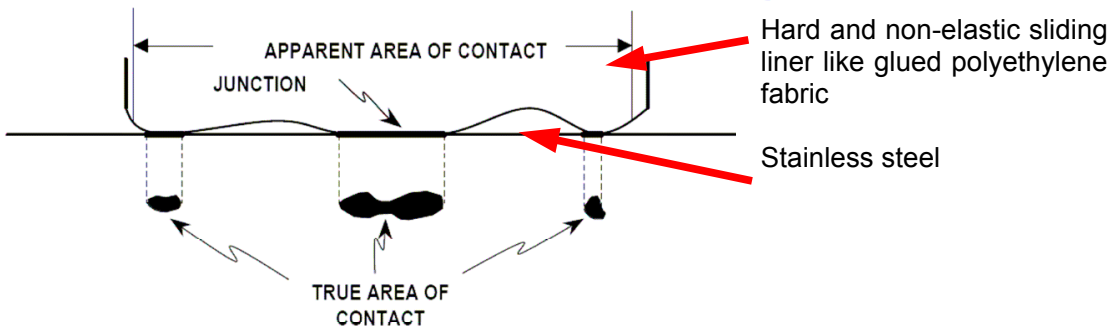

Figure 4: Sketch shows the disparity between the true area of contact and the apparent area of contact in the case of non-elasto-plastic sliding material (Constantinou [7]).

Other pendulum devices on the market operate with thin ( 0.8 to $1.6 \mathrm{~mm}$ thick), hard and non elasto-plastic materials and therefore contact problems with stress peaks on the stainless steel occur (Fig. 4), which end up in scratches of up to $0.5 \mathrm{~mm}$ depth and significant wearing. Finally after one earthquake the bearing needs refurbishment.

The maximum scratch depth for SIP devices on the stainless steel sheet due to sliding displacements is $0.05 \mathrm{~mm}$, which is not influencing the sliding or friction characteristics of the sliding couple. 
The friction characteristic of the sliding couple can be adjusted in the range of $0.5 \%$ to $7 \%$ by variation of the applied stress, i.e. the average load acting onto the isolator. In case of higher friction vales the re-centering of the system is disturbed and higher forces are acting onto the building structure. Therefore friction values higher than $7 \%$ are usually anyway not desired.

In Fig. 5 a 3-cycle displacement test showing the three characteristic hysteretic loops with forces versus displacement. All three loops are more or less on each other.

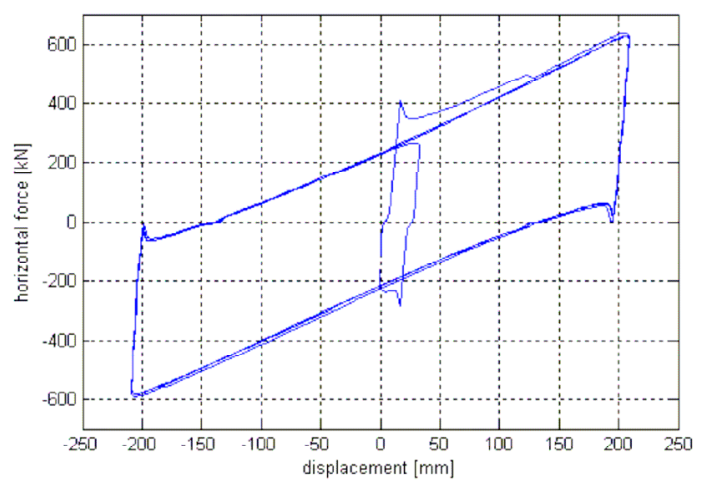

Figure 5: $\quad$ SIP device placed with the sliding surface at the bottom (Benzoni [8]).

\subsection{Wear resistance}

The applied sliding couple of special polyethylene against stainless steel was tested for long term and dynamic behaviour.

The long term test was carried out by the MPA (Material Testing Institute) of the University Stuttgart/Germany. The tests were done with a specimen of $15 \mathrm{x}$ $200 \mathrm{~mm}$ size and another with a disc of $75 \mathrm{~mm}$ diameter, loaded with $60 \mathrm{MPa}$ stress and displaced with $15 \mathrm{~mm} / \mathrm{s}$ velocity, while the accumulated sliding path was 10,000 metres and 50,000 metres. These tests showed neither signs of wear on the special polyethylene nor any abrasions on the stainless steel sheet.

The dynamic testing was carried out at the University of California San Diego in United States of America, which has got a huge testing rig for full scale dynamic testing of isolators. The total simulated dynamic displacement was equal to more than ten earthquakes.

For the full scale test $12,000 \mathrm{kN}$ vertical load was applied on a SIP device. One of the simulations was the magnified EL Centro earthquake with displacements in all horizontal directions, $+/-200 \mathrm{~mm}$ displacement amplitudes and peak velocities faster than $300 \mathrm{~mm} / \mathrm{s}$ while $12,000 \mathrm{kN}$ were applied.

After testing the SIP was dismantled and no wear or any particles on the sliding surface were detected (Fig. 6). Therefore the conclusion can be made that no change in sliding characteristics due to dynamic displacements will occur. Thus the bearing will survive several design earthquakes without damages. 
Insignificant scratches after dynamic testing of $0.05 \mathrm{~mm}$ depth and no further particles on sliding surface

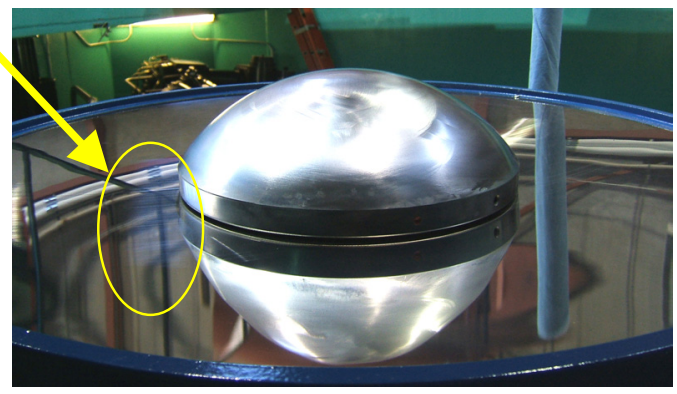

Figure 6: $\quad$ SIP device opened after dynamic testing (Benzoni [8]).

\subsection{Design}

The entire design of the SIP is based on the standard for structural bearings EN1337, the prEN15129 [4] for Anti Seismic Devices and the European Technical Approval for Spherical Bearings with special sliding material [5].

Therefore all materials, tolerances, main geometry, admissible stresses, quality management and testing procedures are specified and fulfilled accordingly, which is unique for a seismic isolator until now.

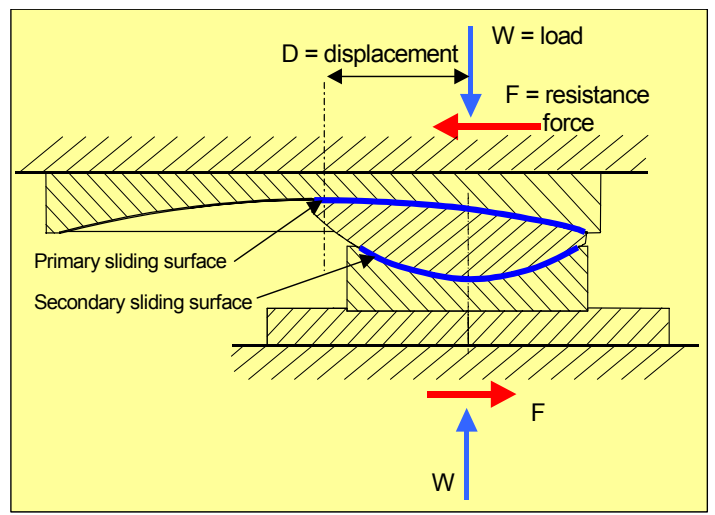

Figure 7: $\quad$ Acting forces on a SIP device.

The sliding couple for the primary and the secondary sliding surface (Fig. 7) provide a well known and defined amount of dynamic friction, adjustable between $\mu=0.005$ and $\mu=0.07$ resulting in a reliable damping ratio $\xi_{\text {eff }}$ of the isolator.

$$
\xi_{\text {eff }}=\frac{2}{\pi} \cdot \frac{\text { area of hysteresis loop }}{\text { area of circumscribed rectangle }}
$$

where

$$
\text { "area of the hysteretic loop" }=4 \cdot \mu \cdot W \cdot D
$$


and

$$
\text { area of the circumscribed rectangle }=4 \cdot K_{\text {eff }} \cdot D^{2}
$$

and effective (peak-to-peak) stiffness is

$$
K_{\text {eff }}=\frac{\Delta F}{\Delta D}=\frac{\left(F_{\max }\right)^{+}-\left(F_{\min }\right)^{-}}{2 \cdot D} \frac{W}{R}+\frac{\mu \cdot W}{D}
$$

Introducing (2), (3) and (4) in (1) we obtain:

$$
\xi_{\text {eff }}=\frac{2}{\pi} \cdot \frac{\mu}{D / R+\mu}=\frac{2}{\pi} \cdot \frac{\mu \cdot R}{(D+\mu \cdot R)}
$$

Considering all design issues, like re-centering, etc., the SIP damping ratios between 0.05 and 0.40 can be realized, which is usually a reasonable damping capability even for severe earthquake impacts.

\section{Applications of SIP devices}

\subsection{New acropolis museum - Athens/Greece}

The New Acropolis Museum is under construction at the south end of the Acropolis and it will be finished most probably end of 2007. The size is approx. $100 \mathrm{~m}$ by $50 \mathrm{~m}$ in plan view. Due to its big windows and the importance of the building the owner, who is the state Organisation for Construction of the New Museum of Acropolis (O.A.N.M.A.), decided to avoid structural damages to go for the solution of seismic isolation with Sliding Isolation Pendulum devices. The isolation system consists of 94 SIPs with an ultimate load capacity of up to $13,600 \mathrm{kN}$ and $+/-255 \mathrm{~mm}$ displacement capability, which are placed at the base floor level (Figs. 8 \& $9 \& 10$ ).

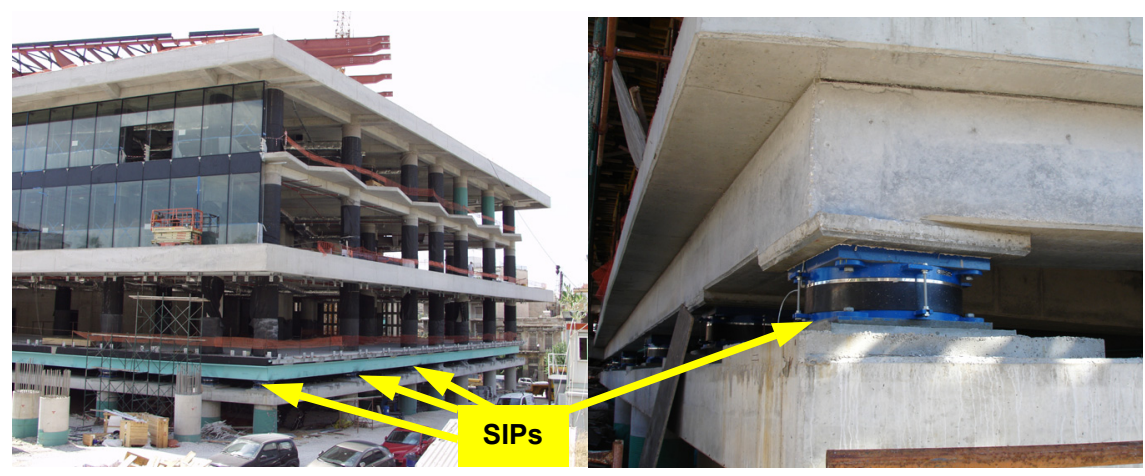

Figure 8: $\quad$ SIPs under the base slab (picture provided by O.A.N.M.A.).

The general seismic design considerations of the structure were based on the Uniform Building Code 1997 (UBC) and the American Concrete Institute Code ACI-318-02 2002.

Therefore all SIPs were designed with a radius of the concave sliding surface of $2,235 \mathrm{~mm}$ creating $2.1 \mathrm{~s}$ to $2.5 \mathrm{~s}$ effective structural period. According to the 
owners design specification the devices are responding at 2,225 $\mathrm{kN}$ vertical load with $5 \%$ friction between the primary sliding couple, at $4,450 \mathrm{kN}$ with $4 \%$ and at $6,675 \mathrm{kN}$ with $3 \%$. The testing series of all of the devices partly in the CALTRANS rig at the UCSD San Diego and partly at the University of Armed Forces Munich was especially focused on the upper and lower bound properties. Thus the first-cycle coefficient of friction must be equal or less than $5 \%$. The average 3-cycle coefficient of friction has to be within the range of $3.5 \%$ to $4.5 \%$. For the seismic calculation $3.5 \%$ friction was considered to establish the displacement demands on the SIP, which were calculated to be $+/-201 \mathrm{~mm}$ and therefore less than the $+/-255 \mathrm{~mm}$ possible displacement. To establish the force demands on the structure $5.5 \%$ friction was assumed.

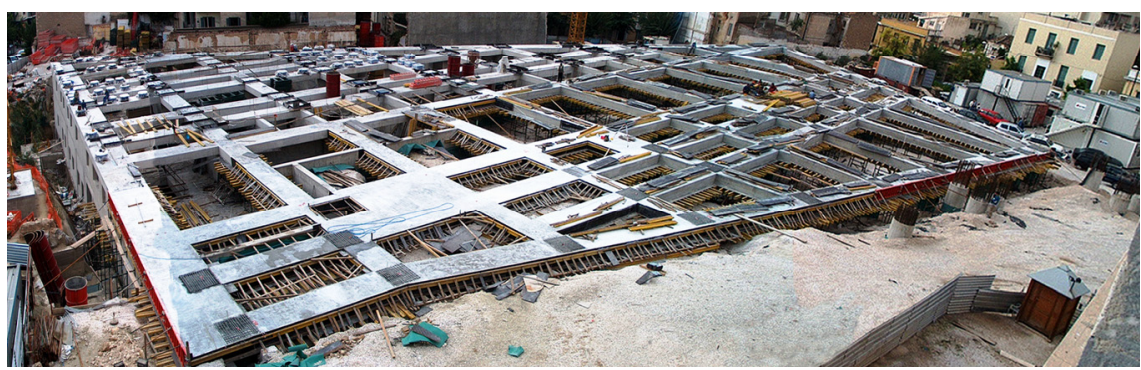

Figure 9: Arrangement of the SIPs on the base floor (picture provided by O.A.N.M.A.).

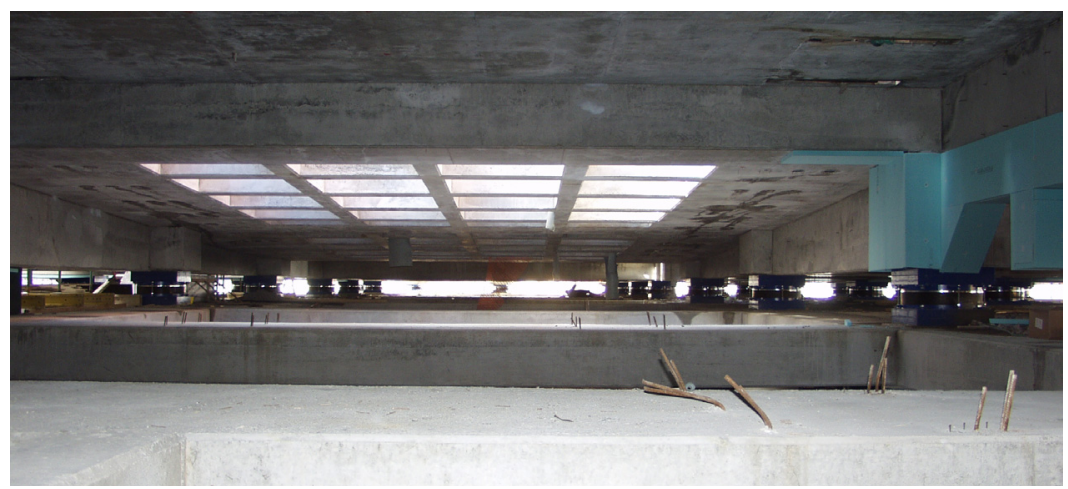

Figure 10: Arrangement of the SIPs between the base floor and the floor slab of the first floor (picture provided by O.A.N.M.A.).

Considering a maximum peak ground acceleration of $0.36 \mathrm{~g}$ (maximum capable earthquake) the maximum acceleration induced into the floors 1,2 and 3 is $0.15 \mathrm{~g}$ only.

The owner carried out his own quality management in addition, visiting the workshop of the devices and participating in all of the prototype and production tests. 


\subsection{Onassis house of letters and fine arts - Athens/Greece}

The ONASSIS Foundation will finish in 2008 the Onassis House of Letters and Fine Arts in Athens, which contains an opera and exhibition spaces (Fig. 11). Its value will be in the range of 75 Mio. Euro. The peak ground acceleration is also in this case at $0.36 \mathrm{~g}$. The maximum acceleration within the building structure was reduced to $0.2 \mathrm{~g}$ by the application of 46 SIPs for an ultimate load capacity of $25 \mathrm{MN}$ (Figs. $11 \& 12$ ). The maximum seismic displacement was calculated to be $195 \mathrm{~mm}$ and the devices where considered for $+/-250 \mathrm{~mm}$ displacement capability.

\subsection{Söğütözü congress centre - Ankara/Turkey}

The Sögütözü Congress Centre in Ankara is the biggest steel construction in Turkey and will be finished in 2008 (Fig. 13). The SIP devices are designed for $3,000 \mathrm{kN}, 6,000 \mathrm{kN}$ and $12,000 \mathrm{kN}$ service loads, while their ultimate capacity is double. The 193 isolators will carry in total $792 \mathrm{MN}$ service load. The size in plan is $280 \mathrm{~m} \times 90 \mathrm{~m}$ offering space for 5100 people. The design displacement at $0.3 \mathrm{~g}$ is considered to be $120 \mathrm{~m}$.

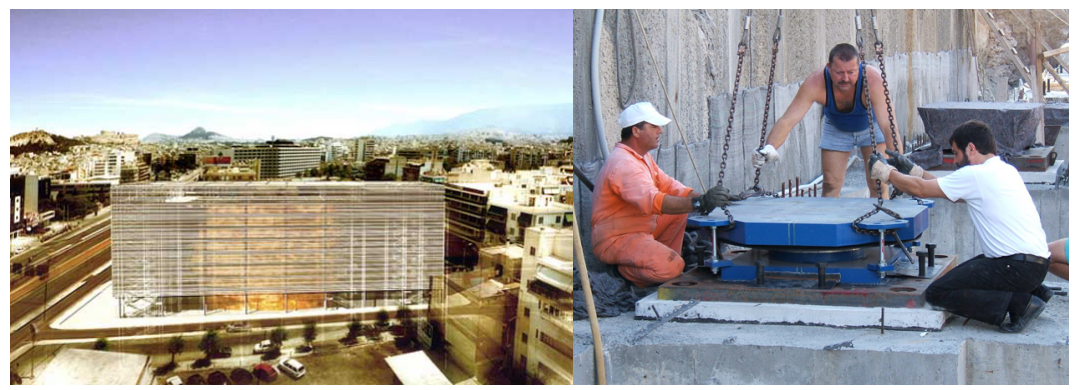

Figure 11: Onassis House of Letter and Fine Arts and bearing installation (picture provided by TENSOR).

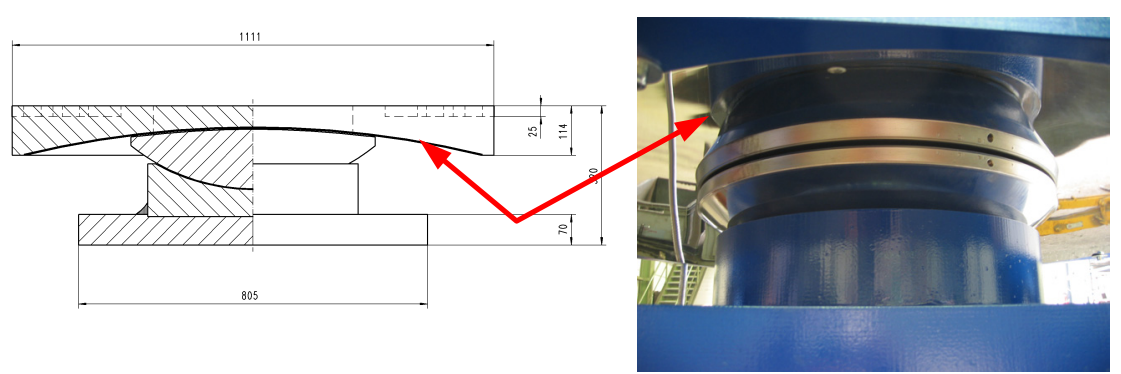

Figure 12: Sketch of the installed SIP devices (left) and primary sliding surface (right). 

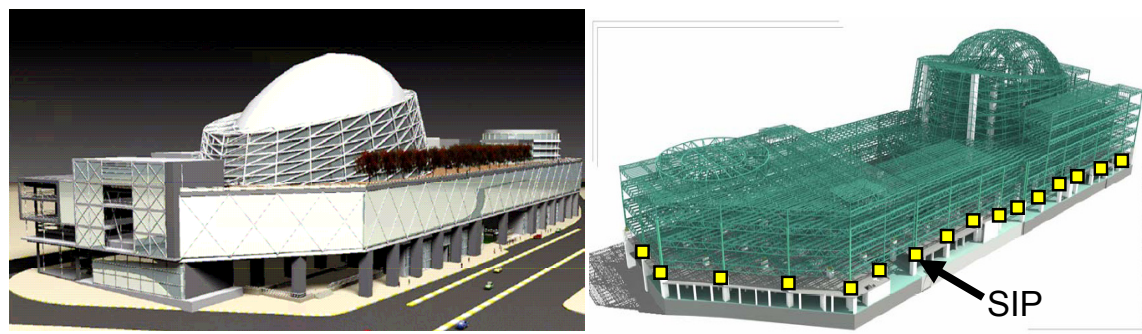

Figure 13: Animation and model of the structure of the Sögütözü Centre.

\section{Conclusions}

The SIP device is the first and only pendulum isolator device with independent full scale testing in all horizontal directions, with independent third party supervision of design and materials, and with conformity to existing European standards and Technical Approvals.

Due to the very good and unique long term performance and constant behaviour the device is considered to have the same service life as the building structure, i.e. 100-120 years, while always granting the best possible seismic protection.

\section{References}

[1] Zayas, Stanley, "Sliding isolation systems and their applications", ASCE Annual Seminar, United Engineering Center, New York, U.S.A., 1995

[2] Braun, Medeot, "Seismic hardware suitable for energy approach design", Seminar on Seismic Isolation, Passive Energy Dissipation and Active Control of Vibrations of Structures, Cheju, Korea, 1999

[3] Medeot, "Re-centring capability evaluation of seismic isolation systems based on energy concepts", 13th World Conference on Earthquake Engineering, Vancouver, Canada, 2004

[4] Medeot, "The European standard on anti-seismic devices", Sixth World Congress on Joints, Bearings and Seismic Systems for Concrete Structures, Halifax, Canada, 2006

[5] MAURER SÖHNE, "European technical approval for spherical bearings with special sliding material - ETA06-0131", EOTA and DIBT, Berlin, Germany, 2006

[6] Braun, Hoppe, Roos, "New high performance sliding material for structural bearing”, Sixth World Congress on Joints, Bearings and Seismic Systems for Concrete Structures, Halifax, Canada, 2006

[7] Constantinou, "Friction pendulum double concave bearing", Technical Report of State University of New York, Buffalo, NY, U.S.A., 2004

[8] Benzoni, Testing reports and comments, Testing Reports for SIPs of the Onassis House of Letters and Fine Arts and the New Acropolis Museum in CALTRANS Testing Rig, University of California San Diego, CA, U.S.A., 2005-2006 